\title{
Utilizing Assessment and Student Experiences to Build a Collaborative Residential Curriculum
}

Kyle C. Flowers, Residential Life, Macalester College

In the 2019-2020 academic year, Macalester College conducted a comprehensive assessment of the college's residential curriculum model through a pedagogical lens. We identified three larger findings: 1) There is a pedagogical misalignment with the implementation of learning strategies in residential areas, 2) Larger, sequential stressors exist for the First-Year and Sophomore Year Experience (FYE \& SOYE), and 3) Campus partners are interested in increasing collaboration within the residential curriculum to improve the student experience. These findings drove larger recommendations centered around a third version of our Community Learning Model (CLM), where learning strategies are sequenced to maximize student learning.

Residential curricular approaches (also called residential curriculums) date back to 2006, when the first residential life department identified the need to focus the student's experience on campus to be driven by learning outcomes rather than by programs (Kerr and Tweedy, 2006). With a focus on backwards design, residential curriculums are vastly different from programming models; professionals have slowly started to shift away from a model where budgets and staff time are utilized to plan large scale events in residence halls. This shift is an increasing trend in higher education and our institution, Macalester College, was one of the early adopters of the change. We have utilized two iterations of a residential curriculum since 2007 and it was important for us to reassess our students' and campus's needs.

A new evolution of the curriculum is motivated for many reasons. We 
know that the demographic of our students is changing - and our current college students are a part of the iGen population, a generation that is more adept to technology, develops at a slower pace, and is consistently engaged with issues on mental health (Twenge, 2017). We also are motivated to focus on a student's sense of mattering while they attend college, and to help them feel important and valued in their community (Schlossberg, 1989). Lastly, we want to continue to focus on a student's sense of belonging through our residential curricular engagement (Strayhorn, 2012).

As a result, in the 20192020 academic year we conducted a comprehensive assessment of the residential curriculum model through a pedagogical lens. With a focus on student learning, we facilitated six assessment techniques focused on four key populations at our institution: residents, resident assistants, campus partners, and our department's professional staff. The six different assessment techniques

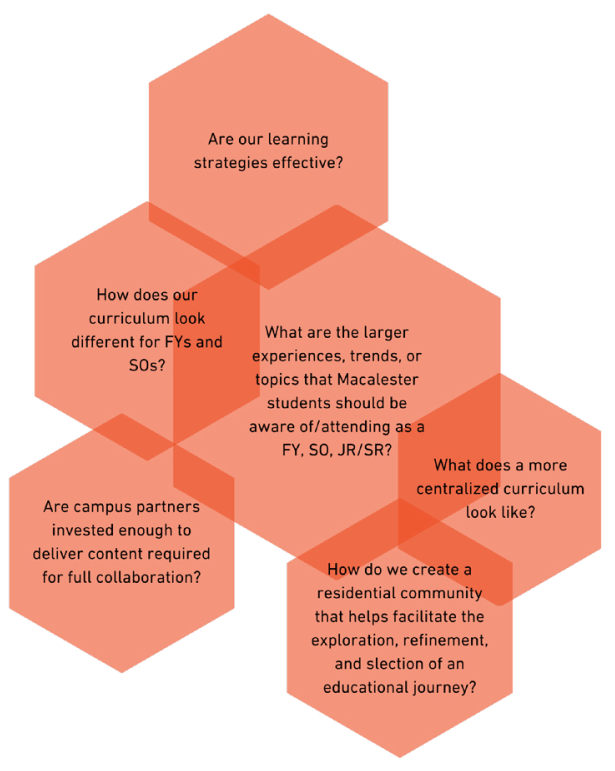
were as follows:

- Graffiti activity during resident assistant training

- Focus groups with campus partners

- Student interactions assessment through 1-on-1 conversations

- Survey on our department's services

- Interviews with our residence hall directors

- Survey to resident assistants regarding their experience of the curriculum

Below is the executive summary of our 2019-2020 assessment. A comprehensive, online report of our findings can be found here: https://drive.google.com/drive/ folders/1wNoR7U3RzsCJKzDivwGdh5ia1QhWHf4C. 
By informed assessment, we learned that our students learn and move through experiences with the following foundations in mind:

1. Identity

2. Community

3. Involvement

4. Well-Being

We believe that while a student may understand their foundations differently as they persist through Macalester, the foundations are everpresent and should be affirmed and acknowledged when we support students living on campus. These foundations are considered individually and should be intentionally woven through our implementation of student learning in residential areas.

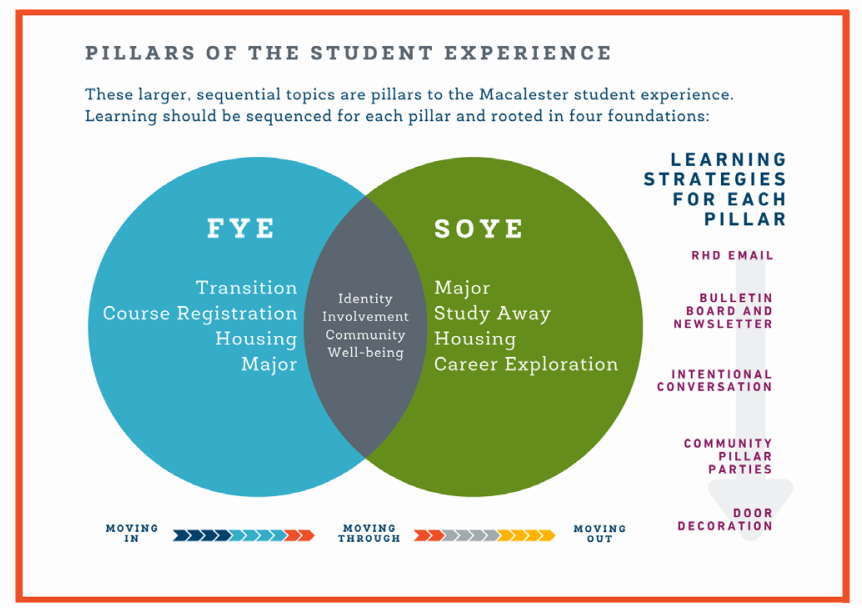

Additionally, we know that our Macalester student experience is unique and unlike any other institution; therefore, it is essential that we plan for and identify experiences that are salient to students each year they live with us. Given our two-year live on requirement, we identified four larger stressors that each student at Macalester moves through during their first-year and sophomore year experience. These are in order of how they most often show up during the year, starting with one at the beginning of the first semester, the middle to end of the first semester, the beginning of the second semester, and middle to end of the second semester. 
- First-Year Experience (FYE)

- Transition

Each student will move into a residence hall on campus and will be individually supported past orientation. At Macalester, we believe that orientation is an event, but a student's transition is a process.

- Course Registration

Each student will select and register for courses for their first time, utilizing support from their academic advisor (FYC instructor) and resources available to them on campus.

- Housing

Each student will be informed and consider their secondyear housing options through the Room Draw process. Additionally, each student will identify what helpful considerations should influence their housing decisions (roommates, style of room, etc.).

- Major

Each student will take part in their major discernment and consider the steps to declare a major. This may include switching academic advisors, considering their interests that align to a future job, and working on developing a plan for future class schedules.

\section{MAC}

RESIDENTIAL LIFE

\section{COMMUNITY LEARNING MODEL} FIRST-YEAR EXPERIENCE

Transition Course Registration Housing Major

- Sophomore Year Experience (SOYE)

- Major

Each student will complete the process of deciding a major and formally apply for major selection in their appropriate department. Additionally, each student will develop a plan for how their future Macalester plans should be shaped with their major in mind. 
- Study Away

Each student will consider what a Study Away experience may look like for them by signing up for an individual advising appointment and/or attending an information session.

○ Housing

Each student will be informed about on-campus living options through Room Draw and decide, if they are interested in living off campus, where and who they will live with.

- Career Exploration

Each student will learn about and utilize resources offered through Career Exploration that may include the MacExplore program, cover letter and resume writing workshops, and internship preparation.

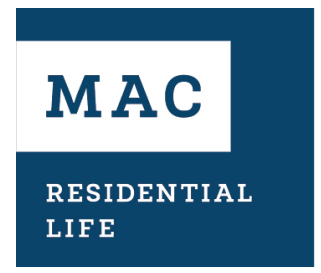

\section{COMMUNITY LEARNING MODEL SOPHOMORE YEAR EXPERIENCE \\ Major Study Away Housing Career Exploration}

After our report outlined the foundations and pillars of our new curriculum, we as a department established a timeline to write the third version of our Community Learning Model (CLM) - the name of our residential curriculum. The writing of the third version consists of developing lesson plans to utilize the following five learning strategies during each pillar of learning. Each pillar is designed for different modes of student learning and will scaffold off of the other pillars. The learning strategies will occur in this order:

1. Residence Hall Director (RHD) Email (Anticipatory Set)

a. An email will be sent by RHDs to the students that is tailored to the specific class year of the student, informing them of the focus and intention for the next 8 weeks.

2. Bulletin Board/Newsletter (Information)

a. Bulletin boards will be organized by resident assistants and developed intentionally to help residents get information 
regarding the pillar's topic. Additionally, the bulletin board material will be made in collaboration with offices/

departments on campus who specialize in that pillar's topic.

3. Intentional Conversation (Reflection and Individualization)

a. Resident assistants will work with all of their residents to have a 30-minute 1-on-1 conversation on the pillar's topic. These conversations help a student begin to reflect on their process of moving through the topic and identify barriers that are in the way of their success. The questions asked in the intentional conversations are rooted in our curriculum's foundations and designed in collaboration with campus partners. We hope to ask a similar core of questions to all students with individualized follow up and support.

4. Community Pillar Party (Assessment)

a. To celebrate the success of a student's persistence in a pillar, resident assistants will organize a Community Pillar Party. These parties can create opportunities of storytelling and affirming experiences within a residential community, and help our staff see if there is additional support to help the resident's experience.

5. Door Decoration Evolution (Accomplishment/Affirmation of Engagement)

a. Lastly, resident assistants will showcase a student's completion of moving through a pillar by enhancing their door decoration. These decorations are individually themed and created by resident assistants.

Additionally, given our strong collaboration with campus partners, we believed that these lesson plans within the curriculum should lift up the work of other departments on campus. Our robust lesson plan timeline includes opportunities for campus partners to provide questions, resources, and edits to our curriculum. The following campus partners are highlighted in the next version of our curriculum: High Winds (offcampus housing), Center for Study Away, Office of Student Leadership and 
Engagement, Career Exploration, and Academic Programs.

Our hope was to complete the third version of the curriculum by August, 2020; however, COVID-19 halted all progress. While our curriculum planning took a back seat to support our students who were navigating their abrupt transition off campus, we were communicative about the opportunity for picking this back up at a later time. We have adapted our timeline to still complete our third version of our Community Learning Model for the next time students are on campus. If anything, our response to COVID-19 has required us to consider better practices for our students when they start living with us again.

Our current and future work on the residential

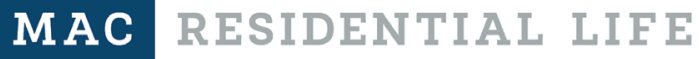
curriculum is grounded through best practices through Google Team Drive. We have developed lesson plan templates through our institutional branding that are easy for our resident assistants to read and access. Additionally, our Residential Life staff are all critical components to the success of the new Community Learning Model; collaboration drives our excitement for the new

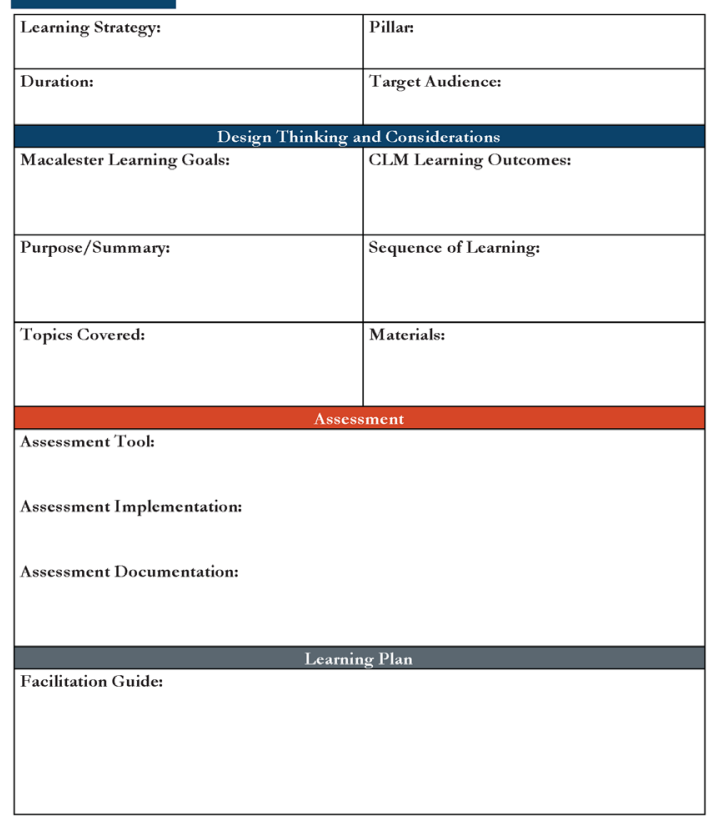
curriculum.

The ultimate success of our new curriculum will depend on how our residents experience and move through the pillars next year. Given our assessment and yearlong process for evaluating the needs of our students, we feel confident that our efforts will aid in our students' mental health, sense of belonging, retention, and community at Macalester. Additional research includes evaluating pillars for our juniors and seniors on campus. 


\section{References}

Kerr, K. G., \& Tweedy, J. (2006). Beyond seat time and student satisfaction: A curricular approach to residential education. About Campus, 11(5), 9-15.

Schlossberg, N.K. (1989). Marginality and mattering: Key issues in building community. New directions for student services, 48(1), 5-15.

Strayhorn, T. L. (2012). Exploring the impact of Facebook and Myspace use on first-year students' sense of belonging and persistence decisions. Journal of College Student Development, 53(6), 783-796.

Twenge, J. M. (2017). iGen: Why today's super-connected kids are growing up less rebellious, more tolerant, less happy--and completely unprepared for adulthood--and what that means for the rest of us. Simon and Schuster. 